\title{
Development of Novel Rice Germplasm for Salt-Tolerance at Seedling Stage Using CRISPR-Cas9
}

\author{
Xiaoli Han ${ }^{1,2,3,+}$, Zhijun Chen ${ }^{1,+}{ }^{,}$, Peide Li ${ }^{1}$, Huashan Xu ${ }^{1}$, Kai Liu ${ }^{1}$, Wenjun Zha ${ }^{1}$, Sanhe Li ${ }^{1}$, Junxiao Chen ${ }^{1}$, \\ Guocai Yang ${ }^{1}$, Jianliang Huang ${ }^{3}$, Aiqing You ${ }^{1,2, *}$ and Lei Zhou ${ }^{1,2, *}$
}

1 Laboratory of Crop Molecular Breeding, Ministry of Agriculture and Rural Affairs, Hubei Key Laboratory of Food Crop Germplasm and Genetic Improvement, Food Crops Institute, Hubei Academy of Agricultural Sciences, Wuhan 430064, China; lilixinyu2007@163.com (X.H.); czj2001@hbaas.com (Z.C.); lipeide2003@hbaas.com (P.L.); xuhuashan1981@hbaas.com (H.X.); liukai11153@hbaas.com (K.L.); zwj_19850202@whu.edu.cn (W.Z.); lisanhe1@hbaas.com (S.L.); cjx881112@hbaas.com (J.C.); yangguocai@hbaas.com (G.Y.)

2 Hubei Hongshan Laboratory, Wuhan 430070, China

3 College of Plant Sciences, Huazhong Agriculture University, Wuhan 430070, China; jhuang@mail.hzau.edu.cn

* Correspondence: for correspondence: aq_you@hbaas.com (A.Y.); zhoulei@hbaas.com (L.Z.)

+ These authors contributed equally to this work.

\section{check for} updates

Citation: Han, X.; Chen, Z.; Li, P.; Xu, H.; Liu, K.; Zha, W.; Li, S.; Chen, J.;

Yang, G.; Huang, J.; et al.

Development of Novel Rice Germplasm for Salt-Tolerance at Seedling Stage Using CRISPR-Cas9. Sustainability 2022, 14, 2621. https:// doi.org/10.3390/su14052621

Academic Editors: Zhong-Hua Chen, Wenying Zhang, Fanrong Zeng and Fenglin Deng

Received: 20 January 2022

Accepted: 22 February 2022

Published: 24 February 2022

Publisher's Note: MDPI stays neutral with regard to jurisdictional claims in published maps and institutional affiliations.

Copyright: (c) 2022 by the authors. Licensee MDPI, Basel, Switzerland. This article is an open access article distributed under the terms and conditions of the Creative Commons Attribution (CC BY) license (https:// creativecommons.org/licenses/by/ $4.0 /)$.

\begin{abstract}
Saline-alkali tolerant rice, as the first selected grain crop for improving coastal tidal land and saline-alkali land, has great potential for comprehensive utilization. In this study, an elite three-line restorer in breeding, R192, was taken as the receptor, and CRISPR/Cas9 technology was used to perform the directional editing of OsRR22, the main effect gene, which controls salt tolerance in rice. Eight transgenic plants of the $\mathrm{T}_{0}$ generation with the OsRR22 gene knockout were obtained, and the transgenic seedlings were screened by using PCR amplification and sequence comparison. The homozygous mutant lines, M16 and M18, with OsRR22 knockout, which did not contain a transgenic vector skeleton, were identified in the $\mathrm{T}_{2}$ generation. There were $+1 \mathrm{bp}$ and $-20 \mathrm{bp}$ in the exon regions of M16 and M18, respectively. At the three-leaf and one-heart stage, the seedlings were treated with $0.4 \%$ and $0.8 \% \mathrm{NaCl}$ solution, and then their salt tolerance during the seedling stage was identified. The results showed that, without the salt treatment, no significant differences were found in plant height, the number of green leaves, total dry weight, and total fresh weight between the mutant lines M16 and M18 and the wildtype (WT) R192. However, after treatment with two different salt concentrations, the M16 and M18 mutants showed extremely significant differences in comparison with WT in plant height, the number of green leaves, total dry weight, and total fresh weight; between mutants and WT, there were significant differences in the number of green leaves, total fresh weight, and total dry weight after two salt treatments. Our results indicate the new germplasm with the OsRR22 mutation induced by CRISPR/Cas9 technology could improve the salt tolerance of rice, providing a reference for the improvement of salt tolerance of rice.
\end{abstract}

Keywords: rice; salt tolerance; germplasm innovation; gene knockout; OsRR22

\section{Introduction}

The area of saline-alkali land worldwide is around 950 million $\mathrm{hm}^{2}$. Due to factors such as global warming, about $20 \%$ of irrigated farmland is salinized and alkalified. In China, the area of existing inland saline-alkali land is nearly 100 million $\mathrm{hm}^{2}$, and the coastal tidal land is 2.34 million $\mathrm{hm}^{2}$ [1]. Saline-alkali land is a rare reserve land resource in China, with huge potential for comprehensive utilization. Increasingly severe soil salinization and secondary salinization have lowered fertility, resulted in the destruction of the originally cultivated land resources, and caused agricultural production to face enormous risk, becoming worldwide ecological problems [2]. As arable land resources become increasingly scarce, how to transform saline-alkali land into high-yield fertile farmland has now 
become one of the main research directions for agricultural scientists [3]. Rice, as the first selected grain crop for improving coastal and saline-alkali land, has tremendous potential for comprehensive utilization. Rice likes sweet soil and is a moderately salt-susceptible crop. Salt stress has detrimental effects on rice molecules, cells, as well as physiological and biochemical levels, resulting in a reduction in rice yield or death [4]. It is one of the significant actions to guarantee world food security via screening and innovating salinealkali tolerant rice germplasm resources, studying the genetic and molecular mechanism of salt-alkali tolerance, cultivating novel rice varieties with saline-alkali-tolerant capacity, and then conducting promotion and application in large areas [5,6].

Numerous salt tolerance quantitative trait loci have been identified, and a few of them have been transferred into popular rice varieties via marker-assisted selection (MAS) [7-9]. During the past two decades, many salt-related genes (SKC1, SNAC1, DST, OsRR22, OsSPL10, STRK1, and SOS1) have been successfully cloned [10-16]. Currently, among the cloned salt-tolerant genes in rice, OsRR22 is one of the most important negative regulatory genes for salt tolerance in rice; this gene encodes the B-type response regulatory protein composed of 696 amino acids, which is located on chromosome 1 of rice and is involved in cytokine signal transduction and metabolism. The deletion of this gene can lead to a significant increase in salt tolerance in rice [13]. Notwithstanding the tremendous advances that have been made in the salt-tolerant breeding of rice in China, there are still many problems to be solved, for instance, the study of salt-tolerant mechanisms in rice, few salt-tolerant genes that can be directly utilized, and the need for further breakthroughs in salt-tolerant breeding approaches and germplasm innovation research. This study expects to knock out the OsRR22 gene using CRISPR/Cas9 technology and obtain a novel rice germplasm with higher salt tolerance, providing new materials for the cultivation of salt-tolerant rice varieties. In this study, the existing elite parents with excellent comprehensive traits were improved to create a novel salt-tolerant rice germplasm by using up-to-date gene-editing technology, which accelerates the process of salt-tolerant rice breeding.

\section{Materials and Methods}

\subsection{Plant Growth Conditions}

The elite indica rice cultivar R192 was bred in our laboratory. All transgenic plants and R192 (wildtype, WT) were grown in the greenhouse at $28-35^{\circ} \mathrm{C}$ or in fields at the station of the Hubei Academy of Agricultural Sciences in Wuchang under normal growth conditions. For salinity stress at the seedling stage, seedlings of rice were cultivated in normal nutrient solution for two weeks after germination on a 96-well plate. They were placed in a growth chamber $\left(14 \mathrm{~h}\right.$ of daytime at $30{ }^{\circ} \mathrm{C}$ and $10 \mathrm{~h}$ at night at $25^{\circ} \mathrm{C}$ with $70 \%$ relative humidity) [13].

\subsection{Vector Construction}

The Cas9 plant expression vector (pYLCRISPR/Cas9Pubi-H) and the sgRNA expression vector ( $\mathrm{pYLgRNA}$ ) were provided by Prof. Yao-Guang Liu of South China Agricultural University (Figure 1). The Cas9-OsRR22-gRNA expressing vector was constructed following the previously described protocol [17]. Briefly, according to the design principles of the target sequences of the CRISPR/Cas9 system, 19 to 20 bases upstream of the protospacer adjacent motif (PAM) were selected as a candidate target sequence (Figure 1).

In this study, Agrobacterium was used to infect the callus of mature rice embryos, with hygromycin as the selection marker. The green regenerated plants were obtained from transformed callus grown on the induction medium. Then, further analysis was conducted. 
$\mathbf{A}$

Os06g0183100

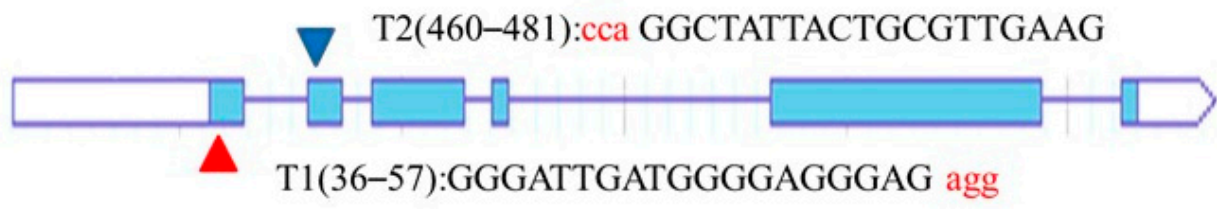

B

$\begin{array}{ll}\text { LB } & \text { RB }\end{array}$

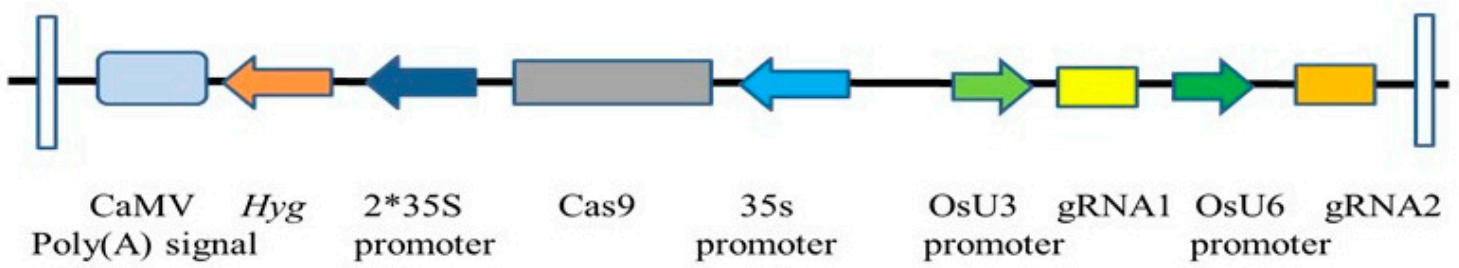

Figure 1. The site of the target sequence and schematic diagram of the cas9-OsRR22 vector. (A). Schematic diagram of the OsRR22(Os06g0183100) gene structure and gRNA targets. (B). Schematic diagram of the cas9-OsRR22 expression vector. LB, vector left border; RB, vector right border; Hyg, the resistance gene of hygromycin; OsU3 promoter, rice U3 promoter; OsU6 promoter, rice U6 promoter; $2 * 35 S$ promoter, two CaMV35S promoter; gRNA scaffold, guide RNA scaffold; Cas9, the gene of Cas9.

\subsection{Detection and Identification of Transgenic Plants}

To identify T-DNA-free plants from $\mathrm{T}_{1}$, the plants were analyzed via PCR using OsRR22-specific and Cas9-specific primers (Table 1) in combination with agarose gel electrophoresis. The $\mathrm{pYLCRISPR/Cas9Pubi-H} \mathrm{plasmids} \mathrm{and} \mathrm{the} \mathrm{T}_{0}$ transgenic plants were selected as positive controls, and R192 DNA and $\mathrm{H}_{2} \mathrm{O}$ were used as negative controls. HygR-and Cas9-negative plants were considered the T-DNA-free plants.

Table 1. Primers used in this study.

\begin{tabular}{cclc}
\hline Name & Forward Primer $\left(\mathbf{5}^{\prime} \mathbf{-} \mathbf{3}^{\prime}\right)$ & \multicolumn{1}{c}{ Reverse Primer $\left(\mathbf{5}^{\prime} \mathbf{- 3}^{\prime} \mathbf{)}\right.$} & Purpose \\
\hline$R R 22-Y$ & cagtGGTCTCaggcagggattgatggggagggag & cagtGGTCTCaaaacctccctcccatcaatccc & Vector construct \\
$R R 22-B$ & cagtGGTCTCatgtgcttcaacgcagtaatagcc & cagtGGTCTCaaaacggctattactgcgttgaag & Vector construct \\
$R R 22-1$ & TCTTGCTGAGAATTGGCTCGAT & AGTTGAGCATCATGGATAGCTGA & Target site sequencing \\
$R R 22-2$ & TGCTTCTGCTTGCATTGTTCA & TCTGAACTTACTGATGACTGGGAGA & Target site sequencing \\
Cas9 & GAACGGTCGTAAGAGGATGCTG & GGTGATGGACTGGTGGATGAGA & Transgenic analysis \\
$H P T$ & GCTCCATACAAGCCAACCACG & CCTGCCTGAAACCGAACTGC & Transgenic analysis \\
\hline
\end{tabular}

A pair of dominant specific primers with a length of $449 \mathrm{bp}$ was designed in accordance with the known Cas9 sequence, and the agarose detection was performed after PCR; two pairs of specific primers were designed for the two target sites. The primer sequences are shown in Table 1. Sequencing for the samples was performed after PCR amplification. PCR amplification system: The $15 \mu \mathrm{L}$ reaction system selected for molecular marker amplification included $11.5 \mu \mathrm{L} \mathrm{ddH}_{2} \mathrm{O}, 1.5 \mu \mathrm{L} 10 \times$ PCR Buffer (containing $\mathrm{Mg}^{2+}$ ), $0.4 \mu \mathrm{L}$ $(10 \mathrm{mM}) \mathrm{dNTP}, 0.2 \mu \mathrm{L}(50 \mu \mathrm{M})$ of each forward and reverse primer, $0.2 \mu \mathrm{L}$ Taq enzyme, and $1 \mu \mathrm{L}$ DNA template $(50 \mathrm{ng} / \mu \mathrm{L})$. The amplification process was as follows: predenaturation at $95{ }^{\circ} \mathrm{C}$ for $33 \mathrm{~min}$; denaturation at $94{ }^{\circ} \mathrm{C}$ for $30 \mathrm{~s}$, denaturation at $55^{\circ} \mathrm{C}$ for $30 \mathrm{~s}$, and extension at $72{ }^{\circ} \mathrm{C}$ for $40 \mathrm{~s}$, with 35 cycles in total. 


\subsection{Identification and Evaluation of Salt Tolerance for Mutant Plants}

To evaluate the salt tolerance of plants at the seedling stage, we carried out a salt stress experiment according to the approach presented in Takagi et al. (2015). Seedlings were placed in an artificial climate box to grow. We compared the salt tolerance of two-week-old WT and homozygous mutant plants. Fresh groundwater, $0.4 \% \mathrm{NaCl}$, and $0.8 \% \mathrm{NaCl}$ $(\mathrm{pH}=7)$ were used to treat the two-week-old plants, respectively. After the two-week treatment, the salt tolerance was tested by measuring the plant height, fresh weight per plant, and dry weight per plant. Ten plants were selected from each material. The experiment was repeated five times.

\subsection{Data Analysis}

Excel and SPSS statistical analysis software were used to analyze all data.

\section{Results and Analysis}

\subsection{Construction of the Recombinant Expression Vector of the OsRR22 Gene in Rice}

The complete nucleotide sequences of the OsRR22 gene (Os06g0183100) were found via the NCBI database, and the two target sites for specific primers were designed in the exon region (Figure 1). The kit was used to quickly and easily insert the gRNA target sequence into the Cas9/gRNA plasmid. The constructed Cas9/gRNA plasmid could simultaneously express the plant codon-optimized Cas9 protein and gRNA. The knockout and editing of the target gene were performed using CRISPR technology. The information of the constructed vector and specific insertion position is shown in Figure 1 (Wuhan Biorun Biotechnology Co., Ltd., Wuhan, China).

\subsection{Acquisition of Transgenic Seedlings and Identification of Homozygotes}

In the $\mathrm{T}_{0}$ generation, eight individual plants with editing positive at the target site were obtained (Figure 2). In the spring of 2019, the $\mathrm{T}_{1}$ generation lines were planted in Hainan. PCR detection and sequencing were carried out. In total, 104 individuals without transgenic vector sequences (T-DNA free) were screened from $349 \mathrm{~T}_{1}$ plants, which were derived from seven $\mathrm{T}_{0}$ families (one $\mathrm{T} 0$ individual plant was sterile). Then, homozygous individual plants were screened by target site examination. The results showed that the mutations were generated at the target site 1 of all eight lines. The analysis of mutation types and mutation genotypes of the $T_{0}$ generation was as follows: from the mutation genotypes, heterozygous mutations, homozygous mutations, and bivalent mutations accounted for $50 \%, 12.5 \%$, and $37.5 \%$, respectively; from the mutation types, the proportion of deletion and insertion were $62.5 \%$ and $12.5 \%$, respectively (see Table 2).

\subsection{Salt Tolerance of Rice OsRR22 Gene Mutant Lines}

To evaluate the salt tolerance phenotype of the line with the OsRR22 knockout, two $\mathrm{T}_{2}$ generation lines of homozygous mutants, M16 and M18, were selected in this study and treated with $0.4 \%$ and $0.8 \% \mathrm{NaCl}$ at the two-week-old seedling stage. Compared with the wildtype (WT), the growth phenotypes of the two mutant lines under the stress of different salt concentrations were better (see Figure 3).

After being treated with $0.4 \% \mathrm{NaCl}$ for two weeks, compared with those without $\mathrm{NaCl}$ treatment, the changes in plant height, the mean number of green leaves, total fresh weight, and total dry weight of WT, M16, and M18 were as follows: the plant height of WT decreased by $32.8 \%$, while the height of M16 and M18 reduced by 29.2 and $23.1 \%$, respectively; the mean number of green leaves of WT declined by $68.7 \%$, whereas that of M16 and M18 dropped by 28.2 and 35.5\%, respectively; the total fresh weight of WT decreased by $70.1 \%$, yet, that of M16 and M18 decreased by 39.7 and 39.5\%, respectively; the total dry weight of WT decreased by $56.1 \%$, while that of M16 and M18 decreased by 29.6 and $26.3 \%$, respectively (see Figure 4). 
A

Line

\#4 Allele1: GGAGAGGAAGGGATTGATGGGGAGG-AGAGGGATCAATTCCC Allele2: GGAGAGGAAGGGATTGATGGG-AGG-AGAGGGATCAATTCCC

\#5 Allele1: GGAGAGGAAGGGATTGAT------GGAGAGGGATCAATTCCC Allele2: GGAGAGGAAGGGATTGATGGGGAGGGGAGAGGGATCAATTCCC

\#6 Allele1: GGAGAGGAAGGGATTGATGGGGAGGGAGAGGGATCAATTCCC Allele2: GGAGAGGAAGGGATTGATGGGGAGG-AGAGGGATCAATTCCC

\#9 Allele1: GGAGAGGAAGGGATTGATGGGGAGGGAGAGGGATCAATTCCC Allele2: GGAGAGGAAGGGATTGATGGGGAGGGGAGAGGGATCAATTCCC

\#10 Allele1/2: GGAGAGGA------------------AGGGATCAATTCCC

\#11 Allele1: GGAGAGGAAGGGATTGATGGGGAGGGAGAGGGATCAATTCCC

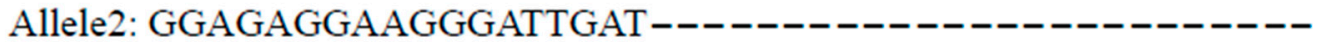
Ref: GGAGAGGAAGGGATTGATGGGGAGGGAGAGGGATCAATTCCC

\section{Line}

\#13 Allele1: TAACATCAACCAACCAGGCTA---CTGCGTTGAAGCTGCTCAG Allele2: TAACATCAACCAACCAGG------CTGCGTTGAAGCTGCTCAG

\#14 Allele1: TAACATCAACCAACCAGGCTATTACTGCGTTGAAGCTGCTCAG Allele2: TAACATCAACCAACCAGGC-A-TACTGCGTTGAAGCTGCTCAG Ref: TAACATCAACCAACCAGGCTATTACTGCGTTGAAGCTGCTCAG

B

Line

\section{Sequence}

\section{Target2}

WT GAAGGGATTGATGGGGAGGGAGAGG...CCAGGCTATTACTGCGTTGAAG

M16 GAAGGGATTGATGGGGAGG-AGAGG...CCAGGCTATTACTGCGTTGAAG

Type

d1

d2

d6

i1

WT

d1

WT

i1

d20

WT

d35

Type

d3

d6

WT

d2

Type

WT

d20

Figure 2. Comparison of the editing target sequences between $\mathrm{T}_{0}$ and $\mathrm{T}_{2}$ transgenic plants. (A) Com-
parison of the editing target sequences between $\mathrm{T}_{0}$ transgenic lines and WT. (B) Comparison of the editing target sequences between $\mathrm{T}_{2}$ homozygous transgenic lines and WT. The targeted sequences are highlighted with underline and the PAM sequences in shadow. The deleted sequences are shown by black hyphens, and the red font represents the insertion bases. i: insertion; d: deletion; WT: wildtype; \#4 to \#14: $\mathrm{T}_{0}$ transgenic lines; M16, M18: $\mathrm{T}_{2}$ homozygous knockout lines with T-DNA-free.

Table 2. Ratios of mutant genotype and mutation type at target site 1 in $\mathrm{T}_{0}$ mutant plants.

\begin{tabular}{ccccc}
\hline \multicolumn{2}{c}{ Proportion of Mutant Genotypes } & \multicolumn{2}{c}{ Proportion of Mutation Types } \\
\hline Bivalent mutation & Heterozygote & Homozygote & Deletion & Insertion \\
\hline $37.5(3 / 8)$ & $50(4 / 8)$ & $12.5(1 / 8)$ & $62.5(10 / 16)$ & $12.5(2 / 16)$ \\
\hline
\end{tabular}

After two weeks of treatment with $0.8 \% \mathrm{NaCl}$, compared with those without $\mathrm{NaCl}$ treatment, the plant height of the WT decreased by $32.7 \%$, while the height of M16 and M18 decreased by 32.3 and 22.6\%, respectively; the mean number of green leaves of the WT decreased by $90.7 \%$; yet, that of M16 and M18 decreased by 51.5 and $53.9 \%$, respectively; the total fresh weight of WT fell by $79.0 \%$, whereas that of M16 and M18 declined by 60.0 
and $48.5 \%$, respectively; the total dry weight of WT was reduced by $59.5 \%$, while that of M16 and M18 decreased by $36.6 \%$ and $21.1 \%$, respectively (see Figure 4 ).

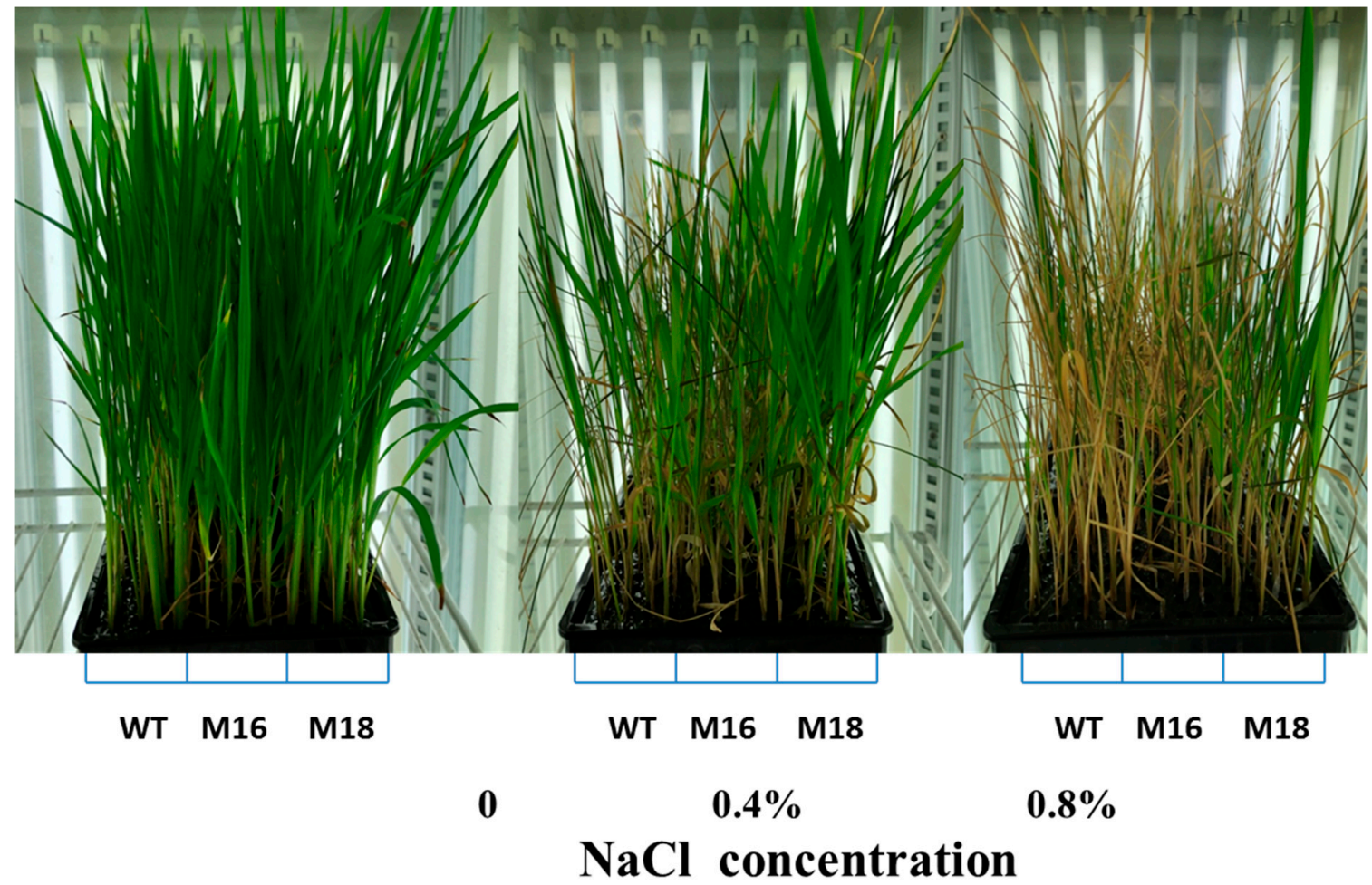

Figure 3. Phenotypes of WT, mutant M16, and mutant M18 before and after seedling salt treatment at seedling stage (Left: before treatment; Middle: after $0.4 \% \mathrm{NaCl}$ treatment; Right: after $0.8 \%$ $\mathrm{NaCl}$ treatment).

According to the analysis of the significance of the difference, without the salt stress treatment, M16 and M18 had no significant differences relative to the WT in plant height, the number of green leaves, total dry weight, and total fresh weight. However, after treatment with two different salt concentrations, M16 and M18 had highly significant differences in comparison with WT in plant height, the number of green leaves, total dry weight, and total fresh weight; the difference in plant height between the mutants and WT under two doses of salt stress was not significant, but the difference in the number of green leaves, total fresh weight, and total dry weight were significant. These results indicate that the salt tolerance of the OsRR22 gene mutants induced by CRISPR/Cas9 technology was enhanced.
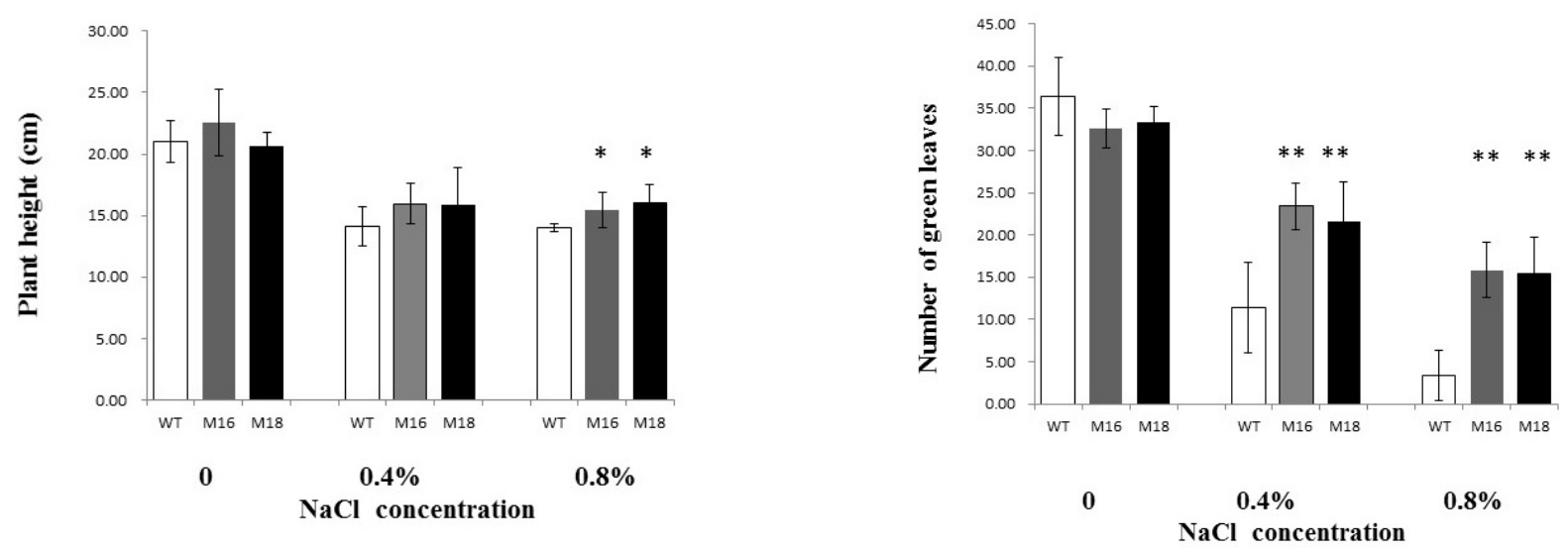

Figure 4. Cont. 

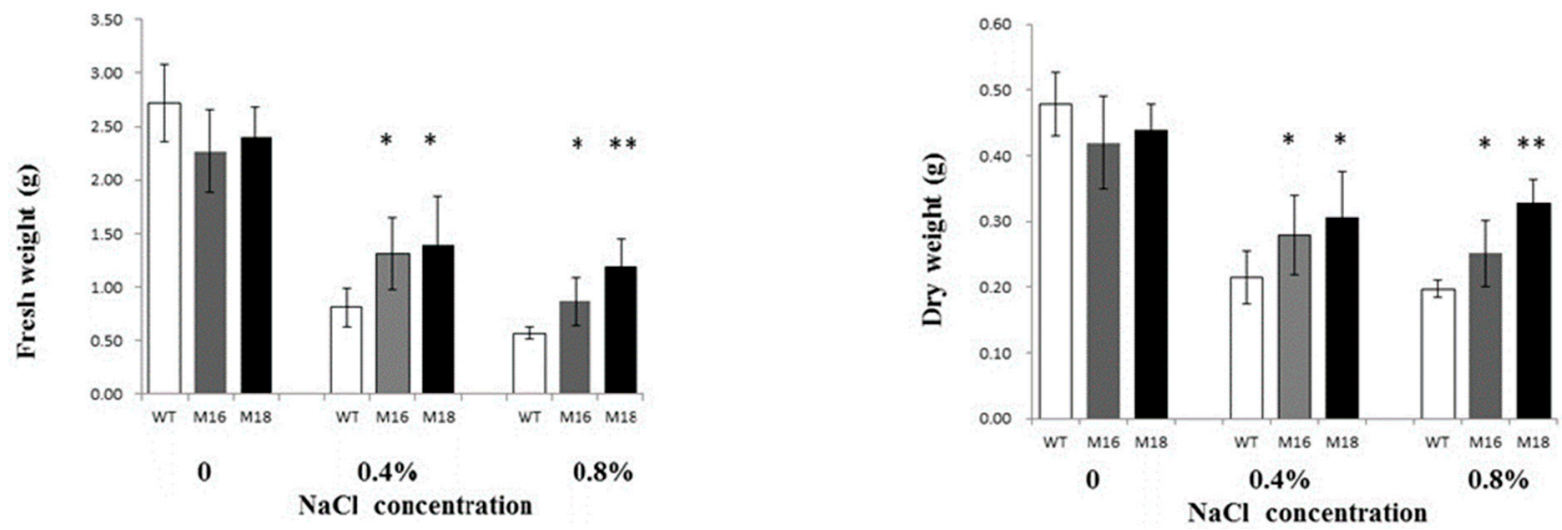

Figure 4. Comparison of plant height, the number of green leaves, total fresh weight, and total dry weight among WT, M16, and M18 after salt treatment at seedling stage. Asterisks indicate significant differences to WT $\left({ }^{*} p<0.01,{ }^{* *} p<0.01\right)$.

\section{Discussion}

\subsection{Creation of Novel Salt-Tolerant Rice Germplasm with OsRR22 Knockout}

CRISPR/Cas9 is a new targeted gene-editing technology with high efficiency and high specificity. To date, CRISPR/Cas9 has been widely applied to the genetic improvement of major crops such as rice, maize, oilseed rape, and soybeans [18]. Nevertheless, there are few studies on gene-targeted editing of elite parents in production via CRISPR/Cas9 technology. In 2020, the Waxy allele of 12 superior inbred lines was edited by CRISPR-Cas9 to create hybrids of waxy corn, a process that was more than a year faster than traditional trait introgression via backcross and marker-assisted selection. Field trials in 25 sites showed that CRISPR-waxy hybrids were superior to introgressed hybrids in agronomic traits, with a mean yield increase of 5.5 bushels per acre [19]. The Badh2 gene was knocked out by CRISPR/CAS9 technology in japonica rice cultivar Zhonghua 11 to obtain the fragrant rice cultivar [20]. The TMS5 gene was knocked out from an elite indica variety, Zhongjiazao 17, and the temperature/photoperiod sensitive male-sterile indica rice line YK17S was cultivated successfully [21].

R192, a three-line indica restorer line of WA cytoplasmic male sterility, was selected by the Food Crops Institute of Hubei Academy of Agricultural Sciences using many parents and crosses, with many advantages including superior quality, high yield, and disease resistance. This study took the parent R192, an elite restorer line, as the material, performed the targeted editing of the OsRR22 gene related to salt tolerance by using the CRISPR/Cas9 approach, and obtained a homozygous mutant line without transgenic components. According to the experimental study that identified salt tolerance at the seedling stage, the plant height, the number of green leaves, total dry weight, and total fresh weight of two mutant lines, M16 and M18, showed highly significant differences relative to those of the WT. This study indicated that the salt tolerance of the novel OsRR22 gene mutant germplasm induced by CRISPR/Cas9 technology was enhanced, which provided a new idea for the improvement of salt tolerance in rice.

\subsection{Research on the Physiological Mechanism of Salt Tolerance in Rice}

Salt stress mainly produces two kinds of stress effects on rice, namely ion stress and osmotic stress [22]. Ion stress results in the enrichment of intracellular sodium ions as well as inhibition of the uptake of potassium and calcium ions, resulting in electrolyte disorder in rice cells and retardation of rice growth [23]. The osmotic stress effect can make it difficult for rice to absorb water from the outside and cause the formation of reactive oxygen species in plant tissues [24]. Reactive oxygen species usually include singlet oxygen, hydrogen peroxide, superoxide, and other toxic substances, which can damage the cell membrane and destroy whole plant growth $[25,26]$. At the same time, salt stress produces the accumulation of osmotic substance proline and lipid peroxidation, which inhibits plant 
growth $[27,28]$. It has also been reported that rice plant growth, photosynthetic pigment, and enzyme activities are affected under salt stress [29]. The physiological function of the OsRR22 gene was studied after obtaining the hst1 mutant of the OsRR22 gene at an earlier stage [30]. Under salt stress, the biomass and growth rate of all rice plants decreased, but the descent degree of the hst1 mutant was less than that of the wildtype; the $\mathrm{K}^{+} / \mathrm{Na}^{+}$ratio of the hst1 mutant under salt stress was higher than that of wildtype; compared with the control, the expression quantity of antioxidant genes including OsAPX1, OsAPX2, OsCATC, and OsSODA in hst1 mutant was significantly enhanced. In terms of vegetative growth (growth rate and amount of growth), photosynthesis, antioxidant enzyme activity, water retention capacity, cell leakage, ion content, organic osmotic solute, and lipid peroxidation, the properties of the hst1 mutant were better than the wildtype. In particular, in the steady state level of the $\mathrm{K}^{+} / \mathrm{Na}^{+}$ratio, the hst1 mutant showed a significant advantage, which indicates that the hst1 mutant may improve its salt tolerance via adjusting the ion pathway.

In this study, we also identified the salt tolerance of M16 and M18 during the sprouting stage and found that there was no significant difference in salt tolerance between these two mutants and their recipient parent R192, a result agreeing with previous studies, namely, no correlation in salt tolerance between the sprouting stage and the seedling stage [31]. According to the results of previous studies, the salt tolerance of rice varieties at the seedling stage was improved by knocking out the OsRR22 gene, which is consistent with the results of this study. For the novel saline-tolerant germplasm, M16 and M18, obtained by improving the elite restorer line, this research provides a theoretical basis and data reference for their promotion and application in saline-alkali land.

Author Contributions: Data curation, H.X., K.L. and S.L.; Investigation, X.H., Z.C., P.L., H.X., W.Z., J.C. and G.Y.; Methodology, X.H. and J.H.; Supervision, J.H., A.Y. and L.Z.; Writing-original draft, X.H. and Z.C.; Writing-review \& editing, A.Y. and L.Z. All authors have read and agreed to the published version of the manuscript.

Funding: This research was funded by the Young Top-notch Talent Cultivation Program of Hubei Province, the Key Science and Technology R\&D Program of Hubei (2020ABA016, 2020BBB051, 2021CFA062), and the Science and Technology Major Program of Hubei Province (2021ABA011).

Institutional Review Board Statement: Not applicable.

Informed Consent Statement: Not applicable.

Data Availability Statement: Not applicable.

Conflicts of Interest: The authors declare no conflict of interest.

\section{References}

1. Li, B.; Wang, Z.C.; Sun, Z.G.; Chen, Y.; Yang, F. Resources and sustainable resource exploitation of salinized land in China. Agric. Res. Arid. Areas 2005, 23, 154-158, (In Chinese with English abstract).

2. Mumns, R.; Gilliham, M. Salinity tolerance of crops-what is the cost? New Phytol. 2015, 208, 668-673. [CrossRef] [PubMed]

3. Ismail, A.M.; Heuer, S.; Thomson, M.J.; Wissuwa, M. Genetic and genomic approaches to develop rice germplasm for problem soils. Plant Mol. Biol. 2007, 65, 547-570. [CrossRef] [PubMed]

4. Grattan, S.R.; Zeng, L.H.; Shannon, M.C.; Roberts, S.R. Rice is more sensitive to salinity than previously thought. Calif. Agric. 2002, 56, 189-198. [CrossRef]

5. Yeo, A.R.; Flowers, T.J. Salinity resistance in rice (Oryza sativa L.) and a pyramiding approach to breeding varieties for saline soils. Aust. J. Plant Physiol. 1986, 13, 161-173. [CrossRef]

6. Hu, T.T.; Liu, C.; Wang, J.K.; Ding, C.W.; Guo, R.L.; Wu, Y.L.; Xu, J.A.; Wang, Y.S. Progress of genetic and breeding on salt tolerance in rice. Mol. Plant Breed. 2009, 7, 110-116, (In Chinese with English abstract).

7. Lang, N.; Buu, B.C.; Ismail, A.M. Enhancing and stabilizing the productivity of salt-affected areas by incorporating genes for tolerance of abiotic stresses in rice. Omonrice 2011, 18, 41-49.

8. $\quad$ Bimpong, I.K.; Manneh, B.; Sock, M.; Diaw, F.; Amoah, N.K.A.; Ismail, A.M.; Gregorio, G.; Singh, R.K.; Wopereis, M. Improving salt tolerance of lowland rice cultivar 'Rassi' through marker-aided backcross breeding in West Africa. Plant Sci. 2016, 242, 288-299. [CrossRef]

9. Jing, W.; Zhang, W. Research progress on gene mapping and cloning for salt tolerance and variety improvement for salt tolerance by molecular marker-assisted selection in rice. Chin. J. Rice Sci. 2017, 31, 111-123, (In Chinese with English abstract). 
10. Ren, Z.H.; Gao, J.P.; Li, L.G.; Cai, X.L.; Huang, W.; Chao, D.Y.; Zhu, M.Z.; Wang, Z.Y.; Luan, S.; Lin, H.X. A rice quantitative trait locus for salt tolerance encodes a sodium transporter. Nat. Genet. 2005, 37, 1141-1146. [CrossRef]

11. Hu, H.H.; Dai, M.Q.; Yao, J.L.; Xiao, B.Z.; Li, X.H.; Zhang, Q.F.; Xiong, L.Z. Overexpressing a NAM, ATAF, and CUC (NAC) transcription factor enhances drought resistance and salt tolerance in rice. Proc. Natl. Acad. Sci. USA 2006, 103, 12987-12992. [CrossRef] [PubMed]

12. Huang, X.Y.; Chao, D.Y.; Gao, J.P.; Zhu, M.Z.; Shi, M.; Lin, H.X. A previously unknown zinc finger protein, DST, regulates drought and salt tolerance in rice via stomatal aperture control. Genes Dev. 2009, 23, 1805-1817. [CrossRef] [PubMed]

13. Takagi, H.; Tamiru, M.; Abe, A.; Yoshida, K.; Uemura, A.; Yaegashi, H.; Obara, T.; Oikawa, K.; Utsushi, H.; Kanzaki, E.; et al MutMap accelerates breeding of a salt-tolerant rice cultivar. Nat. Biotech. 2015, 33, 445-449. [CrossRef] [PubMed]

14. Lan, T.; Zheng, Y.L.; Su, Z.L.; Yu, S.B.; Song, H.B.; Zheng, X.Y.; Lin, G.G.; Wu, W.R. OsSPL10, a SBP-Box Gene, Plays a Dual Role in Salt Tolerance and Trichome Formation in Rice (Oryza sativa L.). G3 2019, 9, 4107-4114. [CrossRef]

15. Zhou, Y.B.; Liu, C.; Tang, D.Y.; Yan, L.; Wang, D.; Yang, Y.Z.; Gui, J.S.; Zhao, X.Y.; Li, L.G.; Tang, X.D.; et al. The receptor-like cytoplasmic kinase STRK1 phosphorylates and activates CATC, thereby regulating $\mathrm{H}_{2} \mathrm{O}_{2}$ homeostasis and improving salt tolerance in rice. Plant Cell 2018, 30, 1100-1118. [CrossRef]

16. Mahi, H.E.; Perez-Hormaeche, J.; Luca, A.D.; Villalta, I.; Espartero, J.; Gamez-Arjona, F.; Fernandez, J.L.; Bundo, M.; Mendoza, I.; Mieulet, D.; et al. A critical role of sodium flux via the plasma membrane $\mathrm{Na}^{+} / \mathrm{H}^{+}$exchanger SOS1 in the salt tolerance of rice. Plant Physiol. 2019, 180, 1046-1065. [CrossRef]

17. Ma, X.; Zhang, Q.; Zhu, Q.; Liu, W.; Chen, Y.; Qiu, R.; Wang, B.; Yang, Z.; Li, H.; Lin, Y.; et al. A robust CRISPR/Cas9 system for convenient, high-efficiency multiplex genome editing in monocot and dicot plants. Mol. Plant 2015, 8, 1274-1284. [CrossRef]

18. Bortesi, L.; Fischer, R. The CRISPR/Cas9 system for plant genome editing and beyond. Biotechnol. Adv. 2015, 33, 41-52. [CrossRef]

19. Gao, H.; Gadlage, M.J.; Lafitte, H.R.; Lenderts, B.; Yang, M.Z.; Schroder, M.; Farrell, J.; Snopek, K.; Peterson, D.; Feigenbutz, L.; et al. Superior field performance of waxy corn engineered using CRISPR-Cas9. Nat. Biotechnol. 2020, 38, 579-581. [CrossRef]

20. Shao, G.N.; Xie, L.H.; Jiao, G.A.; Wei, X.J.; Sheng, Z.H.; Tang, S.Q.; Hu, P.S. CRISPR/CAS9-mediated Editing of the Fragrant Gene Badh2 in Rice. Chin. J. Rice Sci. 2017, 31, 216-222, (In Chinese with English abstract).

21. Barman, H.N.; Sheng, Z.H.; Fiaz, S.; Zhong, M.; Wu, Y.W.; Cai, Y.C.; Wang, W.; Jiao, G.A.; Tang, S.Q.; Wei, X.J.; et al. Generation of a new thermo-sensitive genic male sterile rice line by targeted mutagenesis of TMS5 gene through CRISPR/Cas9 system. BMC Plant Biol. 2019, 19, 109. [CrossRef] [PubMed]

22. Munns, R.; Tester, M. Mechanisms of salinity tolerance. Annu. Rev. Plant Biol. 2008, 59, 651-681. [CrossRef] [PubMed]

23. Wu, H.H.; Zhu, M.; Shabala, L.; Zhou, M.X.; Shabala, S. K+ retention in leaf mesophyll, an overlooked component of salinity tolerance mechanism: A Case study for barley. J. Integr. Plant Biol. 2015, 57, 171-185. [CrossRef] [PubMed]

24. Sharma, P.; Jha, A.B.; Dubey, R.S.; Pessarakli, M. Reactive oxygen species, oxidative damage, and antioxidative defense mechanism in plants under stressful conditions. J. Bot. 2012, 2012, 217037. [CrossRef]

25. Gill, S.S.; Tuteja, N. Reactive oxygen species and antioxidant machinery in abiotic stress tolerance in crop plants. Plant Physiol. Bioch. 2010, 48, 909-930. [CrossRef]

26. Shafi, A.; Chauhan, R.; Gill, T.; Swarnkar, M.K.; Sreenivasulu, Y.; Kumar, S.; Kumar, N.; Shankar, R.; Ahuja, P.S.; Singh, A.K. Expression of $S O D$ and $A P X$ genes positively regulates secondary cell wall biosynthesis and promotes plant growth and yield in Arabidopsis under salt stress. Plant Mol. Biol. 2015, 87, 615-631. [CrossRef]

27. Chawla, S.; Jain, S.; Jain, V. Salinity induced oxidative stress and antioxidant system in salt-tolerant and salt-sensitive cultivars of rice (Oryza sativa L.). J. Plant Biochem. Biot. 2013, 22, 27-34. [CrossRef]

28. Gharsallah, C.; Fakhfakh, H.; Grubb, D.; Gorsane, F. Effect of salt stress on ion concentration, proline content, antioxidant enzyme activities and gene expression in tomato cultivars. AoB Plants 2016, 8, plw055. [CrossRef]

29. Deinlein, U.; Stephan, A.B.; Horie, T.; Luo, W.; Xu, G.; Schroeder, J.I. Plant salt-tolerance mechanisms. Trends Plant Sci. 2014, 19, 371-379. [CrossRef]

30. Niwagaba, P. Physiological and Biochemical Mechanisms of Salt Tolerance in Rice Mutants sst and hst1. Master's Thesis, Fujian Agriculture and Forestry University, Fuzhou, China, 2018.

31. Pan, X.B.; Xie, L.J.; Huang, S.J.; Duan, M.; Chen, J.; Xu, J.L. Salt tolerance and breeding strategy of hybrid rice at different growth stages. Jiangsu Agric. Sci. 2017, 45, 56-60, (In Chinese with English abstract). 